\title{
Association of ionospheric storms and substorms of Global Electron Content with proxy AE index
}

\author{
S.D. Yenen ${ }^{\mathrm{a}, *}$, T.L. Gulyaeva ${ }^{\mathrm{b}}$, F. Arikan ${ }^{\mathrm{a}}$, O. Arikan ${ }^{\mathrm{c}}$ \\ ${ }^{a}$ Department of EEE, Hacettepe University, Beytepe, Ankara 06800, Turkey \\ ${ }^{\mathrm{b}}$ IZMIRAN, Moscow, 142190 Troitsk, Russia \\ ${ }^{\mathrm{c}}$ Department of EEE, Bilkent University, Bilkent, Ankara 06800, Turkey
}

Received 5 May 2015; received in revised form 19 June 2015; accepted 20 June 2015

Available online 26 June 2015

\begin{abstract}
Storm time modeling of Global Electron Content (GEC) calculated from GIM-TEC for 1999-2013 is associated with new proxy of Auroral Electrojet variability expressed as a smoothed and normalized Auroral Electrojet index $\left(A E_{s n}\right)$. The variability in GEC is captured by the computation of DGEC which is obtained by taking the hourly ratio of instant GEC to median of GEC values at the same hour of 7 preceding days. The storm onset is determined by a joint analysis of variations in IMF-B magnitude, its derivative (dB/dt) and direction of IMF-Bz together with sudden increase in AE exceeding $900 \mathrm{nT}$. The start of the pre-storm period is chosen to be $7 \mathrm{~h}$ prior to the storm onset time and the storm recovery period ends $41 \mathrm{~h}$ after the storm onset. The hourly $A E_{s n}$ is related to DGEC during the storm period through a polynomial whose coefficients are estimated in the linear least squares sense. Estimated coefficients are examined and grouped with respect to different kinds of auroral storms. Examples of modeling methodology are provided using four different kinds of intense storms and substorms, namely, Positive Arctic, Positive Antarctic, Negative Arctic and Negative Antarctic that occurred between 1999 and 2013. The estimated coefficients for storm periods are compared with those of non-storm periods. It is observed that the positive correlation between the increase of AE and GEC can be a promising precursor of space weather variability.
\end{abstract}

(C) 2015 COSPAR. Published by Elsevier Ltd. All rights reserved.

Keywords: Ionosphere; Global Electron Content (GEC); Total Electron Content (TEC); Auroral Electrojet (AE) index; Space weather; Geomagnetic storms

\section{Introduction}

Global Electron Content (GEC), which is equal to the total number of electrons in the ionosphere and plasmasphere up to the height of Global Positioning System (GPS) satellite altitude of $20,200 \mathrm{~km}$ (Afraimovich et al., 2008), proved itself to be an indicator of global ionospheric storms and substorms that occur due to the coupling of solar wind to earth's magnetosphere and ionosphere rather

\footnotetext{
* Corresponding author. Tel.: +90 3122977000; fax: +90 3122992125.

E-mail addresses: s.d.yenen@gmail.com (S.D. Yenen), gulyaeva@ izmiran.ru (T.L. Gulyaeva), arikan@hacettepe.edu.tr (F. Arikan), oarikan@ee.bilkent.edu.tr (O. Arikan).
}

than redistribution of electron density within ionosphere and plasmasphere shells (Gulyaeva and Veselovsky, 2012). GEC is a complicated function of solar, annual, seasonal, daily and hourly variability of interplanetary space, magnetosphere, plasmasphere and ionosphere. In that sense, it is connected to Auroral Electrojet (AE) index, which is a measure of global electrojet activity in the auroral zone (Davis and Sugiura, 1966; Hajkowicz, 1998; Weygand et al., 2014). The AE index is derived from geomagnetic variations in the horizontal component of the geomagnetic field along the auroral zone in the northern hemisphere. AE index is measured by the magnetometers it represents the currents in the ionosphere at the altitudes 
near $100 \mathrm{~km}$ above the Earth, namely $\mathrm{AE}=\mathrm{AU}-\mathrm{AL}$ being a span between the eastward (AU) and westward (AL) electrojects in the ionospheric E-layer. While the physical meaning of AE has been under debate (Kamide and Rostoker, 2004), a relationship between the injection of particles to auroral cusp zones by the geomagnetic storms and reaction due to these activities has been observed in various geomagnetic indices (Liu et al., 2011; Buonsanto, 1999; Gulyaeva and Stanislawska, 2008, Gulyaeva and Stanislawska 2010; Gulyaeva et al., 2014). According to the studies in the literature, when high-speed solar wind interacts with the magnetosphere, the Auroral Electrojet (AE) index increases sharply due to global ionospheric electric fields, which in turn can generate strong internal gravity waves propagating from high to lower latitudes (Hajkowicz, 1999; Deminova et al., 1998; Bowman and Mortimer, 2010).

Ionosphere variability is one of priorities for the past and current investigations due to severe modification of trans-ionospheric signals by highly variable plasma density in space and time, thus affecting the positioning and navigation systems (Schrijver et al., 2015). In this study, the response of GEC to a geomagnetic storm is modeled through a polynomial relationship with respect to the proxy AE index. GEC is included into the model after being modified using a median normalization with respect to the values 7 days prior to the storm day as DGEC. The proxy AE index is smoothed during the storm hours with a sliding window median filter of $7 \mathrm{~h}$. Since DGEC is unitless, smoothed $\mathrm{AE}$ is normalized $\left(A E_{s n}\right)$ with respect to the largest value within the storm duration (Section 2). The coefficients of the linear relationship are obtained in Least Square (LS) sense. The coefficients of the polynomial model are estimated for all AE storms that occurred between 1999 and 2013.

Examples of DGEC and AE structural model are provided for Positive Arctic (PAr), Positive Antarctic (PAn), Negative Arctic (NAr), and Negative Antarctic (NAn) substorms that occurred between 1999 and 2013. The positive storm is defined with respect to the increase in ionization and electron concentration due to the entry of particles and energy. The measure and distribution of a positive storm is decided with the magnitude of $\mathrm{Wp}$ index and $\mathrm{W}$-index which is discussed in Gulyaeva and Stanislawska (2010). For a positive storm, $\mathrm{W}$-index values are +3 and +4 that indicates moderate and severe increase. When the regions with positive disturbance are located in North Polar latitudes, then the storm is designated as a Positive Arctic storm. For the Negative Arctic storms, W-index values are -3 and -4 , that indicate a severe depletion in electron density. For Positive and Negative Antarctic storms, W-index values of \pm 3 and \pm 4 occur in South Polar Latitudes, in the Southern Auroral zone. The developed method is applied to all AE storms and an example non-storm period. It is observed that quiet ionospheric conditions differ from geomagnetic storms by investigating the coefficients of the event periods. A storm time model can be proposed using the mean and median of the coefficients of polynomial representation for PAr, NAr, PAn, NAn storm types. The methodology for the proposed relationship is provided in Section 3. Results are given in Section 4.

\section{Specification of proxy AE index}

In this section, the proxy $\mathrm{AE}$ index is described. $\mathrm{AE}$ index is generally provided with a time resolution of $1 \mathrm{~h}$ in the unit of nanoTesla (nT) (http://wdc.kugi.kyoto-u.ac. $\mathrm{jp} / \mathrm{wdc} /$ ). In the investigation of all geomagnetic storms between January 1, 1999 and December 31, 2013, it has been observed that in some disturbances, $\mathrm{AE}$ index increases over $900 \mathrm{nT}$ following the increase in IMF and turning of $\mathrm{z}$ component of IMF-B (IMF-Bz) to the negative value. In this study, such disturbances are designated as AE storms and included into the analysis. In some geomagnetic storms, the disturbance starts and ends within $48 \mathrm{~h}$ or longer. We designated this kind of disturbance as a storm, while substorm is a more fast event lasting 3 to $6 \mathrm{~h}$. In geomagnetic storms that lasts longer than $48 \mathrm{~h}$, there may be cases where the value of $\mathrm{AE}$ increases and decreases more than once. Then these kinds of storms are bounded within $48 \mathrm{~h}$ durations.

The storm onset time is determined with respect to the increase in IMF-B and the time derivative of IMF-B $(\mathrm{dB} / \mathrm{dt})$, along with the turning of IMF-Bz towards negative which are accompanied by the increase of AE either simultaneously or within a few hours. The determination of storm onset time is explained in detail in Section 4. After the storm onset time, the value of AE index increases suddenly but there can be significant small scale variabilities which do not change the trend of increase but can alter the automatic decision of rate of AE increase. In order to avoid the misdetection or wrong decision by the algorithm, we wanted to base our decision of $\mathrm{AE}$ increase during a storm period by a smoothed $\mathrm{AE}$ value which captures the trend and avoids smaller scale variability. In order to achieve that we have implemented a median filter in a sliding window (swmf) with different window lengths. After the investigation of 92 chosen $\mathrm{AE}$ storms, we have decided that a $7 \mathrm{~h}$ sliding window length sufficiently encaptures the trend and it gives the minimum least squares percentage error. Therefore, the smoothed trend structure of $\mathrm{AE}$ is computed as given in the equation below:

$A E_{\text {med }}=$ median $\left\{A E\left(n_{h}-3\right), \ldots, A E\left(n_{h}\right), \ldots, A E\left(n_{h}+3\right)\right\}$

The smoothed AE values of $A E_{\text {med }}$ are normalized within the storm duration $N_{s t}$ and smoothed and normalized values are obtained as a proxy $A E_{s n}\left(n_{s t}\right)$ :

$A E_{s n}\left(n_{s t}\right)=A E_{\text {med }}\left(n_{s t}\right) / \max \left(A E_{\text {med }}\left(N_{s t}\right)\right)$

where $1 \leqslant n_{s t} \leqslant N_{s t}$, and $N_{s t}$ is the storm duration in hours.

In this study, 2240 storms and substorms listed in http:// www.izmiran.ru/ionosphere/weather/storm/ from 1999 to 2013 are investigated. These storms/substorms are grouped 
into Positive/Negative Arctic and Positive/Negative Antarctic with respect to $\mathrm{Wp}$-index magnitude and distribution of $\mathrm{W}$-index with respect to latitude. When these storm periods are correlated with IMF-B and IMF-Bz values, it has been observed that the storm onset that leads to an $\mathrm{AE}$ storm can be best decided with respect to the increase in IMF-B, $\mathrm{dB} / \mathrm{dt}$, and direction of IMF-Bz where $A E$ values increase either simultaneously or after a few hours of the sudden movement in IMF-B. Typically, for the storms where $\mathrm{AE}$ values are over $900 \mathrm{nT}$, the effect of the storm and/or substorm subsides within $40 \mathrm{~h}$ after the storm onset. In order to observe the variability and the sudden increase in AE after the storm onset, a pre-storm period is included. This way, the sharp variation in AE is fully covered and the contrast before, during and after the storm onset can be captured properly. It has been observed that the prestorm period of $7 \mathrm{~h}$ is a reasonable time that separates a single storm or substorm from the previous ones. Therefore, a heuristic storm time period of $7 \mathrm{~h}$ of pre-storm, storm onset time and $40 \mathrm{~h}$ of storm and recovery periods are set to investigate the variability of AE index within a storm period total of $48 \mathrm{~h}$. Thus, in this study, $N_{s t}$ is chosen to be $48 \mathrm{~h}$.

We investigate an occurrence of AE storms with threshold for the smoothed $A E_{\text {med }} \geqslant 900 \mathrm{nT}$. With this threshold, 92 storms are detected during the period from January 1, 1999 to December 31, 2013. The collection of AE storms is plotted in Fig. $\quad 1 \mathrm{a}-\mathrm{c}$ including the original AE index in Fig. 1a, smoothed $A E_{\text {med }}$ variation in Fig. $1 \mathrm{~b}$ and the proxy $A E_{s n}$ index in Fig. 1c. Hour-to-hour median is indicated with a dark solid line. The standard deviation over and under the median is indicated with dashed lines. The range between the standard deviation lines represents the typical pattern of an AE storm. The optimum $A E_{\text {med }}$ storm onset time $\left(t_{0}=0\right)$ is found to be $8 \mathrm{~h}$ before the storm peak (Fig. 1b) which is seen $1 \mathrm{~h}$ earlier at the pattern of the original AE data (Fig. 1a). Also, the peak of the source AE storm is observed $6 \mathrm{~h}$ after the storm onset. Smoothing of AE with $7 \mathrm{~h}$ running window produces lower upper envelope of the index curves as compared with the source hourly AE index while the peaks of the pattern curves (dark line) for the both sets are very close to each other. According to the normalization, the proxy $A E_{s n}$ varies from 0 to 1 with $A E_{s n}=1$ specifying the storm peak in Fig. 1c.

Definition of criteria for the onset of the ionospheric storm of Global Electron Content (GEC) is more involved depending not only on climatological features of the AE index storm but also based on the interplanetary sources as it will be shown in the subsequent sections.

\section{Modeling of GEC dependence on proxy AE index, $A E_{s n}$}

In this section, the dependence of GEC on proxy $\mathrm{AE}$ index is represented using a polynomial model whose coefficients are determined using the linear least squares method. For this purpose, GEC values are normalized with the median of 7 prior days to increase the significance of the variability. For each day, $d$, and hour, $n_{h}$, between January 1, 1999 and December 31, 2013, GEC values, $G E C_{d}\left(n_{h}\right)$, are divided to the median of seven day prior GEC values to obtain $D G E C_{d}\left(n_{h}\right)$ as given in Eq. (3):

$$
\begin{aligned}
& \operatorname{DGEC}_{d}\left(n_{h}\right) \\
& =\frac{G E C_{d}\left(n_{h}\right)}{\operatorname{median}\left\{G E C_{d-7}\left(n_{h}\right), G E C_{d-6}\left(n_{h}\right), G E C_{d-5}\left(n_{h}\right), \ldots, G E C_{d-1}\left(n_{h}\right)\right\}}(3)
\end{aligned}
$$

where $D G E C_{d}\left(n_{h}\right)$ indicates the ratio for day $d$ and hour $n_{h}$. Here, the hour index is $1 \leqslant n_{h} \leqslant 24$ counting 0 to $23 \mathrm{~h}$ in UT. DGEC data from 1999 to 2013 for each day and every hour are ordered in a continuous data set starting from January 1, 1999 to December 31, 2013.
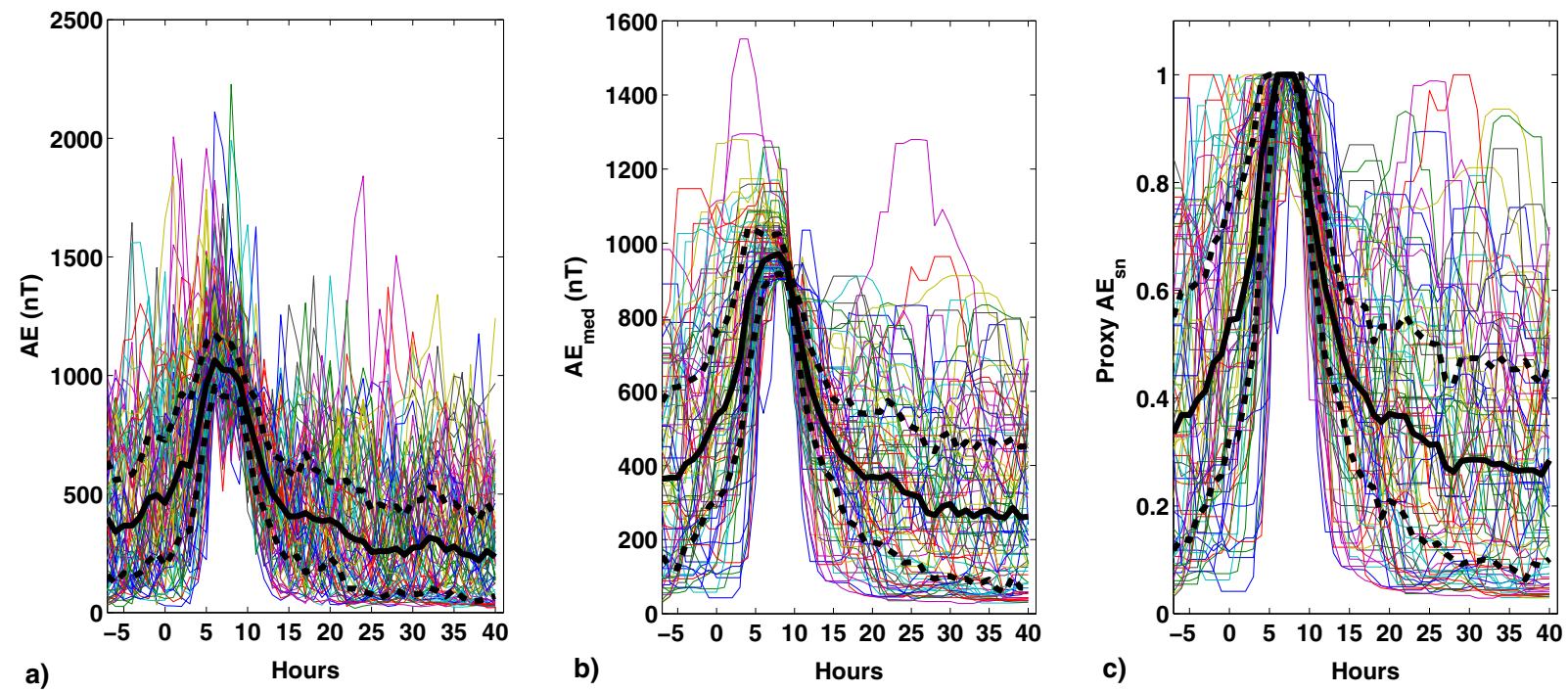

Fig. 1. Collection of AE storms during 1999-2013 represented by (a) original AE index, (b) 7 h smoothed $A E_{m e d}$ index, (c) proxy AE index, $A E_{s n}$. The storm onset time is indicated with $0 \mathrm{~h}$. 
Within the period of 1999-2013, the storm durations of $48 \mathrm{~h}$ are extracted from the DGEC data and modeled with respect to the proxy $A E_{s n}$ as

$D G E C_{s t}\left(n_{s t}\right)=C_{0}+C_{1} A E_{s n}\left(n_{s t}\right)+C_{2} A E_{s n}^{2}\left(n_{s t}\right)$

In the above equation, the index $n_{s t}$ represents the storm hours where its value varies from 1 to 48 . The subscript $s t$ indicates the DGEC values during a storm period and it can be given as

$\underline{D G E C_{s t}}=\left[D G E C_{s t}(1) \ldots D G E C_{s t}\left(n_{s t}\right) \ldots D G E C_{s t}\left(N_{s t}\right)\right]^{T}$

where $1 \leqslant n_{s t} \leqslant N_{s t}$ and $N_{s t}=48$ in this study. For a given storm hour $\left(n_{s t}\right)$, DGEC values for that storm and hour, $D G E C_{s t}\left(n_{s t}\right)$ can be modeled using a polynomial combination of $A E_{s n}\left(n_{s t}\right)$ and $A E_{s n}^{2}\left(n_{s t}\right)$ as given in Eq. (3) where $A E_{s n}\left(n_{s t}\right)$ denotes the normalized median filtered $\mathrm{AE}$ values for storm hours, $n_{s t}$, as

$\underline{A E_{s n}}=\left[A E_{s n}(1) \ldots A E_{s n}\left(n_{s t}\right) \ldots A E_{s n}\left(N_{s t}\right)\right]^{T}$

The square of $A E_{s n}$ in the quadratic model, $A E_{s n}^{2}$, can be ordered as

$\underline{A E_{s n s}}=\left[A E_{s n}^{2}(1) \ldots A E_{s n}^{2}\left(n_{s t}\right) \ldots A E_{s n}^{2}\left(N_{s t}\right)\right]^{T}$

In order to find the coefficients $C_{0}, C_{1}$ and $C_{2}$, the values of $D G E C_{s t}\left(n_{s t}\right), A E_{s n}\left(n_{s t}\right)$ and $A E_{s n}^{2}\left(n_{s t}\right)$ are related with each other for all storm hours, $n_{s t}$. In the above equations the superscript $T$ denotes the transpose operator.

Eq. (4) can be put in a matrix notation as

$$
\left[\begin{array}{ccc}
1 & A E_{s n}(1) & A E_{s n}^{2}(1) \\
\vdots & \vdots & \vdots \\
1 & A E_{s n}\left(n_{s t}\right) & A E_{s n}^{2}\left(n_{s t}\right) \\
\vdots & \vdots & \vdots \\
1 & A E_{s n}\left(N_{s t}\right) & A E_{s n}^{2}\left(N_{s t}\right)
\end{array}\right]\left[\begin{array}{c}
C_{0} \\
C_{1} \\
C_{2}
\end{array}\right]=\left[\begin{array}{c}
D G E C_{s t}(1) \\
\vdots \\
D G E C_{s t}\left(n_{s t}\right) \\
\vdots \\
D G E C_{s t}\left(N_{s t}\right)
\end{array}\right]
$$

where $\underline{C}=\left[C_{0} C_{1} C_{2}\right]^{\mathrm{T}}$. The Least Square (LS) sense solution to Eq. (8) can be obtained as:

$\underline{\hat{C}}=\left(\boldsymbol{A}^{T} \boldsymbol{A}\right)^{-1} \boldsymbol{A}^{T} \underline{D G E C_{s t}}$

where

$$
\boldsymbol{A}=\left[\begin{array}{ccc}
1 & A E_{s n}(1) & A E_{s n s}(1) \\
\vdots & \vdots & \vdots \\
1 & A E_{s n}\left(n_{s t}\right) & A E_{s n s}\left(n_{s t}\right) \\
\vdots & \vdots & \vdots \\
1 & A E_{s n}\left(N_{s t}\right) & A E_{s n s}\left(N_{s t}\right)
\end{array}\right]
$$

and the estimates of the coefficient vector $\underline{C}, \underline{\hat{C}}$, is denoted by

$$
\hat{\underline{C}}=\left[\begin{array}{l}
\hat{C}_{0} \\
\hat{C}_{1} \\
\hat{C}_{2}
\end{array}\right]
$$

The estimated $\underline{D G E C_{s t}}, \underline{\widehat{D G E} C_{s t}}$, can be found by putting $\underline{\hat{C}}$ into Eq. (4) as,

$\widehat{D G E} C_{s t}\left(n_{s t}\right)=\hat{C}_{0}+\hat{C}_{1} A E_{s n}\left(n_{s t}\right)+\hat{C}_{2} A E_{s n s}\left(n_{s t}\right)$

For every storm, the error between the DGEC values and the estimated model values can be calculated using

$e_{m}=\frac{\| \underline{D E E C_{s t}-\underline{D G E} C_{s t} \|_{2}}}{\| \underline{D G E C_{s t} \|_{2}}} \times 100$

where $\|.\|_{2}$ denotes the metric distance between two vectors. In the next section, the proposed modeling method is demonstrated using different types of storms and the model coefficients are obtained for geomagnetic storms between 1999 and 2013.

\section{Results}

In this section, the relationship between the proxy $\mathrm{AE}$ index, $A E_{s n}$, and the GEC is obtained for geomagnetic storms that raised AE index over $900 \mathrm{nT}$ between 1999 and 2013. The methodology for modeling storm time dependency of GEC on AE index is demonstrated using examples from four different kinds of storms, namely, PAr, NAr, PAn, and NAn. The model is also tested on non-storm periods and the difference in coefficient estimates indicates the increasing variability during storm periods. GEC values are calculated using Global Ionospheric Maps (GIM) of Total Electron Content (TEC) as described in detail in Gulyaeva and Veselovsky (2012). Recently, using the algorithm in Gulyaeva and Veselovsky (2012), a data base of GEC between 1999 and 2013 is established.

The ionospheric and plasmaspheric storms can be separated into different categories as discussed in Gulyaeva et al. (2015). In this study, we have concentrated on positive and Negative Arctic and Antarctic ionosphere storms given in the lists of Positive Arctic (PAr), Positive Antarctic (PAn), Negative Arctic (NAr), and Negative Antarctic (NAn) that occurred between 1999 and 2013 at IZMIRAN (2015). Criteria for construction of catalogues of the positive and negative ionosphere storms and substorms (PAr, NAr, PAn, and NAn) in the North (Arctic) and South (Antarctic) zones are provided in Gulyaeva et al. (2015). The ionosphere storm lists are prepared based on planetary storm index $\mathrm{Wp}$ as described in Gulyaeva and Stanislawska $(2008,2010)$ and used in Gulyaeva et al. $(2013,2014)$ as an ionospheric storm indicator. Since there are different kinds of geomagnetic storms, the effects of ionospheric disturbance can exhibit different types of variability on geomagnetic indices (Prölss, 1993; Saba et al., 1997; Fuller-Rowell et al., 1997; Zhao et al., 2007; Malik et al., 2010; Gulyaeva et al., 2014). 
The GEC storm conditions are defined similar to those given in Tsagouri and Belehaki (2008) with modification in the determination of storm onset. Ionospheric storm time disturbances are triggered by Interplanetary Magnetic Field (IMF) and they can be characterized by an increase in IMF magnitude, IMF-B, and/or time derivative of IMF-B, dB/dt, accompanied by a southward turning of the IMF-Bz component. The latter is detected either simultaneously or a few hours later than the increase in IMF-B (Tsagouri and Belehaki, 2008). In this study, the storm onset time, $t_{0}$, for GEC storms is determined using the following conditions:

(i) The IMF-B should increase by $5.5 \mathrm{nT}$ in $3 \mathrm{~h}$ or derivative values of IMF-B should record an hourly increase larger than $3.8 \mathrm{nT}$;

(ii) IMF-Bz should be turned southward ( $\mathrm{Bz}<-1 \mathrm{nT})$ either simultaneously or few hours later than the increase in IMF-B. The value should stay under $-1 \mathrm{nT}$ for at least $3 \mathrm{~h}$;

(iii) $\mathrm{AE}_{\text {med }}$ should be greater than $900 \mathrm{nT}$ either simultaneously or few hours later than the increase indicated in (i) and (ii);

The period for GEC pre-storm study starts $7 \mathrm{~h}$ earlier of storm onset time as $\left(t_{0}-7 \mathrm{~h}\right)$. Each storm period ends at $\left(t_{0}+41 \mathrm{~h}\right)$. After the storm onset, IMF-Bz is turned northward $(\mathrm{Bz}>0 \mathrm{nT})$ within $\left(t_{0}+41 \mathrm{~h}\right)$. Therefore, the storm duration is taken to be $48 \mathrm{~h}$ for all storms/substorms that are under investigation. When the storm conditions including AE values are imposed on the lists given in IZMIRAN (2015), 'AE storms' can be extracted.

The non-storm periods are determined by excluding time periods satisfying the storm conditions determined for AE storms and for days where $A E_{\text {med }}$ is below $60 \mathrm{nT}$, $\mathrm{Kp}$ is below 2 and Dst is between $-10 \mathrm{nT}$ and $10 \mathrm{nT}$. Non-storm periods are taken to be continuous $48 \mathrm{~h}$ that satisfy the above conditions.
In order to model the dependency of DGEC on AE index, the methodology defined in Section 3 is used on the storms in which AE index responded to the IMF parameters and exceeded the value of $900 \mathrm{nT}$ after the storm onset time. Eq. (9) results are computed for each storm duration $N_{s t}=48 \mathrm{~h}$. The IMF-B, Bz for each storm are obtained from http://omniweb.gsfc.nasa.gov/form/dx1. html, AE, Dst and Kp index values are downloaded from http://wdc.kugi.kyoto-u.ac.jp/wdc/. The percentages of different types of storms that have $A E_{\text {med }}>900 \mathrm{nT}$ and satisfy the IMF conditions given above and also the mean $(\mu)$, median $(\eta)$ and standard deviation $(\sigma)$ of estimated AE storm coefficients are provided in Table 1 . The variability of coefficient estimates is highly visible with different kinds of storms. Although $\hat{C}_{0}$ values are close to each other for PAr, NAr, PAn, and NAn storms, $\hat{C}_{1}$, and $\hat{C}_{2}$ values are the smallest for PAr, and the largest for NAr storms. The coefficients of Antarctic storms are very similar to each other exhibiting no discrepancy in the estimated mean and median values. The standard deviations for $\hat{C}_{1}$, and $\hat{C}_{2}$ for all storm types are very large indicating the high variability in the linear and quadratic terms.

From the narrowed down lists mentioned in Table 1, four example storms for PAr, NAr, PAn, and NAn are chosen as denoted in Table 2. For each storm in Table 2, these values are plotted in Figs. 2-5 in subplots a-d, respectively. The GEC, $D G E C_{s t}, A E_{\text {med }}$, and $D \hat{G E} C_{s t}$ are provided in Figs. 2-5 in subplots e- $\mathrm{h}$, respectively. Mean percentage error $\left(e_{\mu}\right)$ is error found for storm times by using mean coefficients in Table 1 . The estimated coefficients, model error and mean error are provided for each storm in Table 2.

The model coefficients are also computed for 13 non-storm periods. One example is chosen as November 10, 2009 01:00 UT to November 12, 2001 00:00 UT, and the estimated coefficients and model error is provided in Table 3. Mean percentage error $\left(e_{\mu}\right)$ for the non-storm period is obtained when the mean coefficient estimates in

Table 1

Percentage of 'AE storms' $\left(A E_{m e d}>900 \mathrm{nT}\right)$ storms in (IZMIRAN, 2015) storm lists, mean $(\mu)$, median $(\eta)$ and standard deviation $(\sigma)$ of AE Storm coefficients.

\begin{tabular}{|c|c|c|c|c|c|c|c|c|c|c|c|c|}
\hline & \multicolumn{3}{|c|}{ PAr (\%3.69) } & \multicolumn{3}{|c|}{ NAr (\%7.40) } & \multicolumn{3}{|c|}{ PAn (\%4.19) } & \multicolumn{3}{|c|}{ NAn $(\% 3.46)$} \\
\hline & $\mu$ & $\eta$ & $\sigma$ & $\mu$ & $\eta$ & $\sigma$ & $\mu$ & $\eta$ & $\sigma$ & $\mu$ & $\eta$ & $\sigma$ \\
\hline$\overline{\hat{C}_{0}}$ & 1.0077 & 1.0161 & 0.0688 & 0.9945 & 1.0045 & 0.0668 & 1.0092 & 1.0200 & 0.0709 & 1.0003 & 1.0133 & 0.0681 \\
\hline$\hat{C}_{1}$ & -0.0719 & -0.1223 & 0.1927 & -0.1314 & -0.1352 & 0.2187 & -0.1121 & -0.1421 & 0.2200 & -0.1137 & -0.1137 & 0.2247 \\
\hline$\hat{C}_{2}$ & 0.0444 & 0.0735 & 0.1485 & 0.0809 & 0.1110 & 0.1846 & 0.0642 & 0.1093 & 0.1833 & 0.0666 & 0.0848 & 0.1910 \\
\hline
\end{tabular}

Table 2

Selected PAr, NAr, PAn, and NAn storms, onset times and durations.

\begin{tabular}{llll}
\hline Storm number & Type & Storm onset time, $t_{0}$ & Storm duration \\
\hline Storm 1 & Par & Nov 24, 2001 06:00 UT & Nov 23, 2001 23:00 UT-Nov 25, 2001 22:00 UT \\
Storm 2 & Nar & Jun 25, 2000 23:00 UT & Jun 25, 2000 16:00 UT-Jun 27, 2000 15:00 UT \\
Storm 3 & Pan & Aug 17, 2003 13:00 UT & Aug 17, 2003 06:00 UT-Aug 19, 2003 05:00 UT \\
Storm 4 & Nan & Jan 21, 2005 16:00 UT & Jan 21, 2005 09:00 UT-Jan 23, 2005 08:00 UT \\
\hline
\end{tabular}




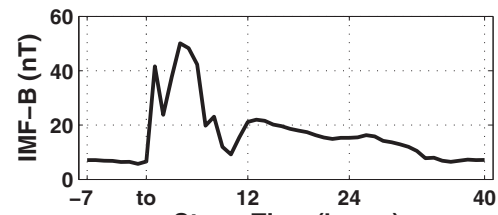

a)

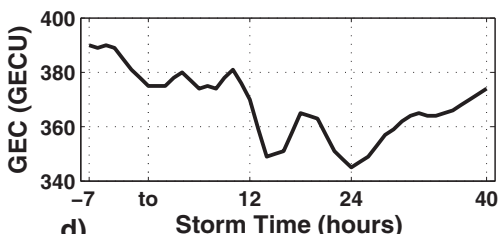

d) Storm Time (hours)

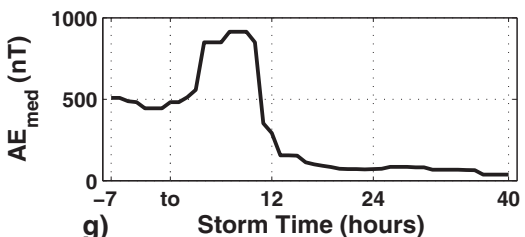

g)

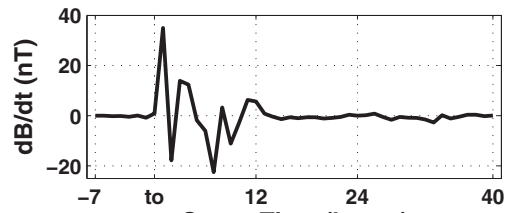

b)

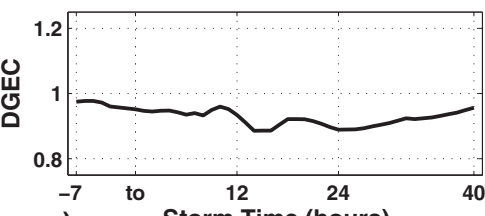

e)

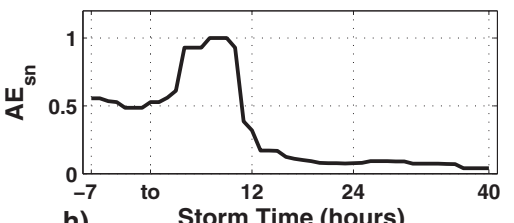

h)

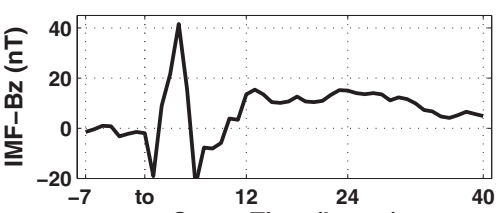

c) Storm Time (hours)

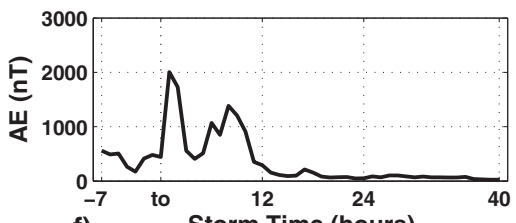

f) Storm Time (hours)

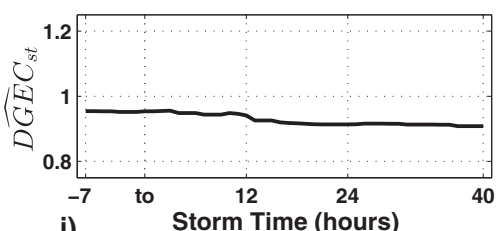

i)

Fig. 2. Storm 1, (a) IMF-B, (b) dB/dt, c) IMF-Bz, (d) GEC, (e) DGEC, (f) AE, (g) $A E_{\text {med }}$, (h) $A E_{s n}$, (i) $\widehat{D G E} C_{s t}$.
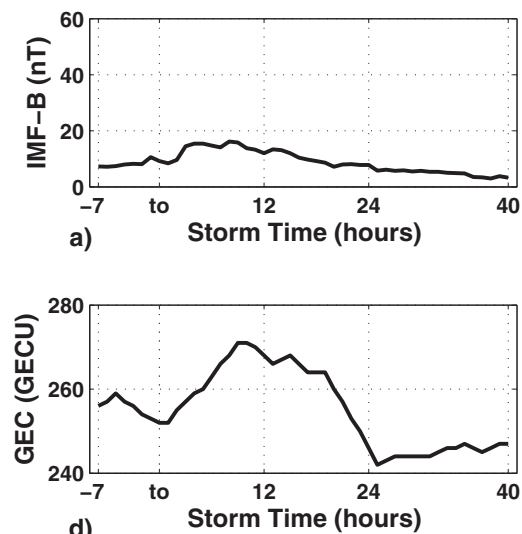

d)

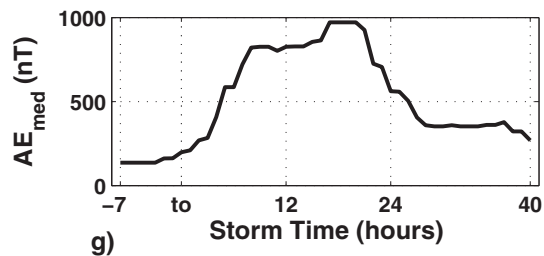

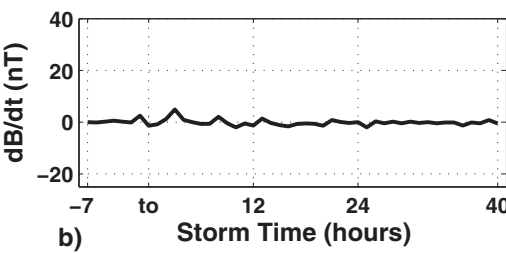

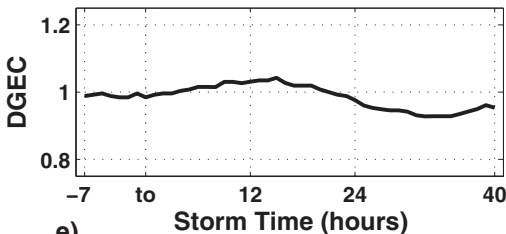

e)

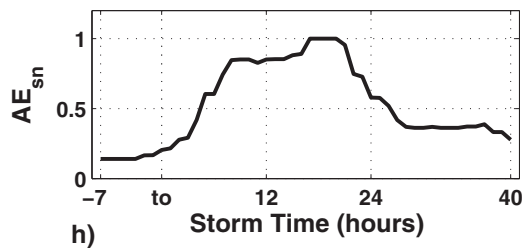

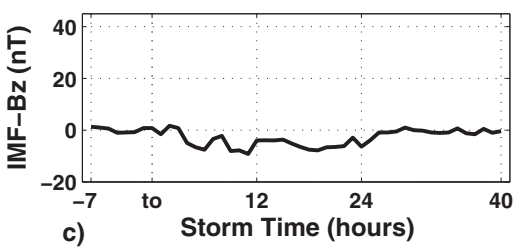
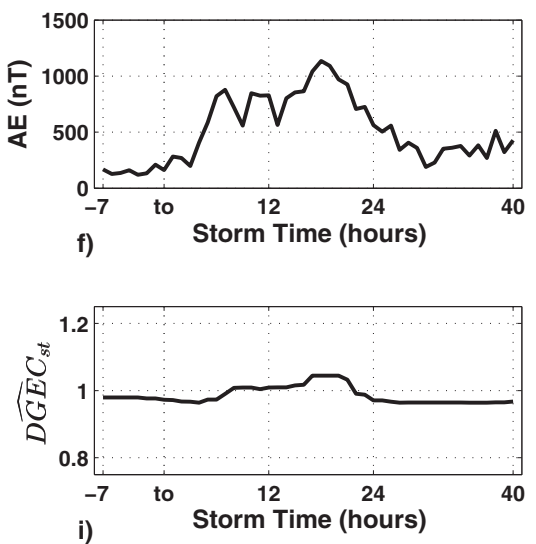

Fig. 3. Storm 2, (a) IMF-B, (b) dB/dt, (c) IMF-Bz, (d) GEC, (e) DGEC, (f) AE, (g) $A E_{\text {med }}$, (h) $A E_{s n}$, (i) $\widehat{D G E} C_{s t}$.

Table 1 are used in the model for non-storm DGEC and AE values.

When the estimated coefficient and percentage error values in Table 3 are examined, it can be observed that the most dominant coefficient is $C_{0}$. The linear and quadratic dependency on proxy AE index differs for storm and non-storm periods. The coefficient $C_{0}$ in Eq. (4) is the level value and it is called the 'nugget' in spatial interpolation terminology. It is observed that the estimate $\hat{C}_{0}$ (in Table 3 and Figs. 8 and 9) is the dominant value by comparing the magnitudes of the coefficient estimates in
Table 1 and 3 and Figs. 8 and 9. The physical meaning is that the first order and second order variations of proxy AE index are not as significant as the nugget value. The variability in DGEC is directly related to proxy $\mathrm{AE}$ and the first and second order variability only bring a correction to this value. While DGEC varies below and above 1 , the proxy AE index is normalized and varies between 0 and 1 . The estimates of the coefficients vary within bounds of comparable correction for the nugget effect. When the first order (linear term) coefficient estimate $\hat{C}_{1}$ and second order (quadratic term) coefficient estimate $\hat{C}_{2}$ have values 


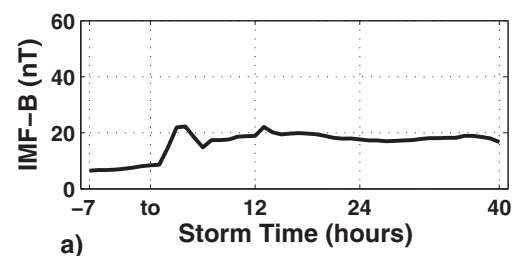

a)

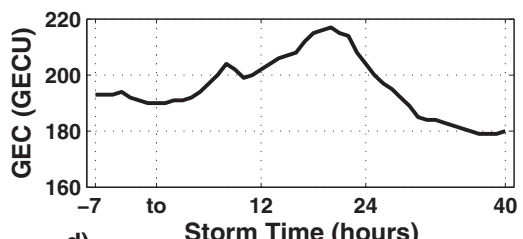

d)

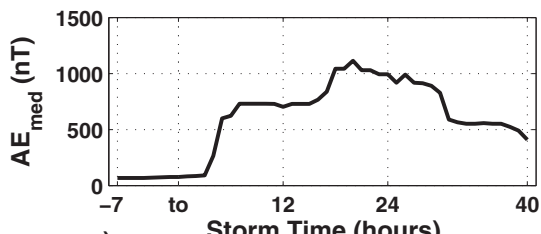

g)

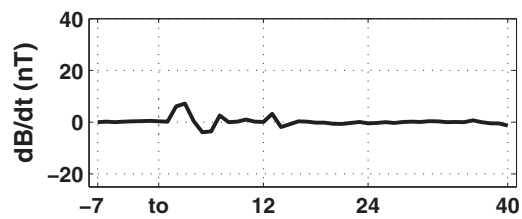

b)

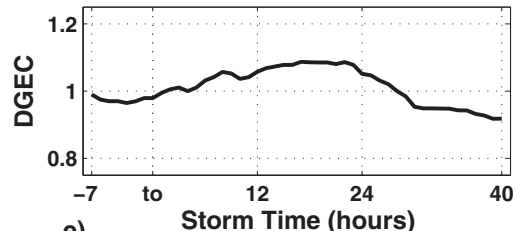

e)

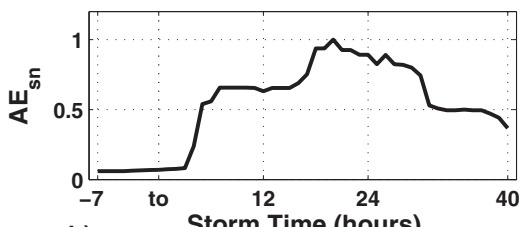

h) Storm Time (hours
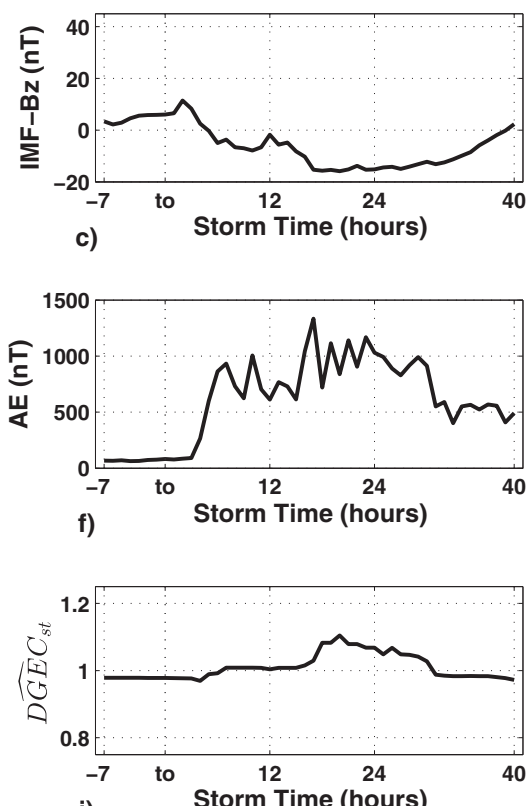

i) Storm Time (hours)

Fig. 4. Storm 3, (a) IMF-B, (b) dB/dt, (c) IMF-Bz, (d) GEC, (e) DGEC, (f) AE, (g) $A E_{m e d}$, (h) $A E_{s n}$, (i) $\widehat{D G E} C_{s t}$.
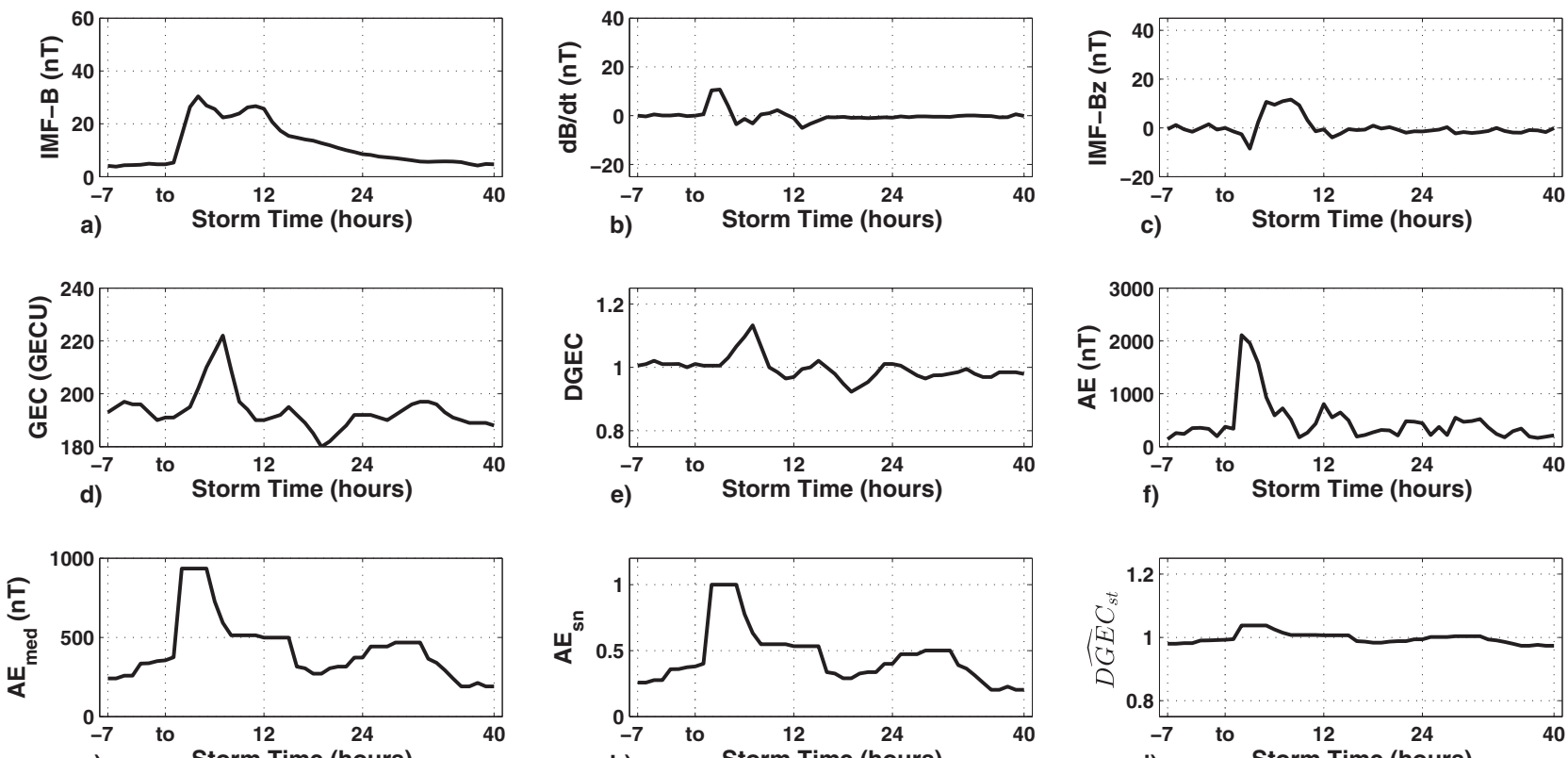

g) Storm Time (hours)

h)

Storm Time (hours)

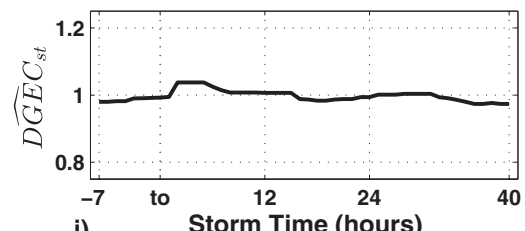

Fig. 5. Storm 4, (a) IMF-B, (b) dB/dt, (c) IMF-Bz, (d) GEC, (e) DGEC, (f) AE, (g) $A E_{\text {med }}$, (h) $A E_{s n}$, (i) $\widehat{D G E} C_{s t}$.

larger than the coefficient estimate $\hat{C}_{0}$, it means that the storm causes significant variability that is represented in the first or second order terms.

The example storms in Table 2 can be better observed individually in Figs. 2-5. The Kp and Dst indices during the storm periods are presented in Fig. 7.

Storm 1 in Fig. 2 is a Positive Arctic (PAr) storm and IMF-B has double peak during storm period. $\mathrm{Kp}$ is larger than 8 i.u. (index units) and Dst index gets as low as $-221 \mathrm{nT}$ as indicated in Fig. 7.

Storm 2 in Fig. 3 is a Negative Arctic (NAr) storm where the onset time is determined by both IMF-B and
$\mathrm{dB} / \mathrm{dt}$ simultaneously. Kp gets as large as 6 i.u. and Dst index gets as low as $-80 \mathrm{nT}$.

Storm 3 in Fig. 4 is a Positive Antarctic (PAn) storm and IMF-B has one major peak during storm period. The increase in IMF-B coincides with the increase in $\mathrm{dB} / \mathrm{dt}$. Kp gets as large as 7 i.u. and Dst index gets as low as $-148 \mathrm{nT}$.

Storm 4 in Fig. 5 is a Negative Antarctic (NAn) storm, where the storm onset is determined by the increase in IMF-B. The increase in $\mathrm{dB} / \mathrm{dt}$ takes place later than storm onset time. During this storm Kp gets as large as 8 i.u. and Dst index gets as low as $-100 \mathrm{nT}$. 
Table 3

Estimated coefficients and model error for storms given in Table 2 and a non-storm period.

\begin{tabular}{llrrr}
\hline Storm number & $\hat{C}_{0}$ & $\hat{C}_{1}$ & $\hat{C}_{2}$ & $e_{m}(\%)$ \\
\hline Storm 1 & 0.9019 & 0.1605 & -0.1187 & 2.05 \\
Storm 2 & 1.0003 & -0.1809 & 0.2249 & 2.39 \\
Storm 3 & 0.9852 & -0.1246 & 0.2436 & 3.78 \\
Storm 4 & 0.9490 & 0.1295 & -0.0409 & 3.25 \\
Example non-storm period & 1.1889 & -0.4673 & 0.3177 & 7.16 \\
\hline
\end{tabular}

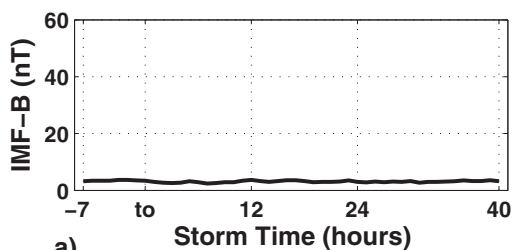

a)
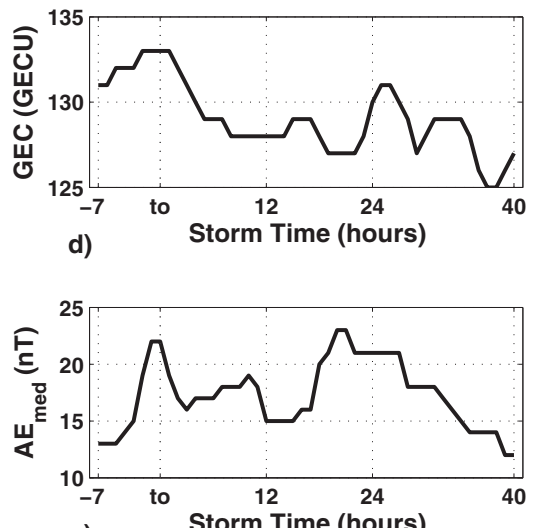

g)

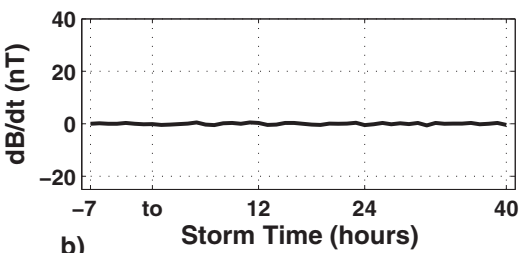

b)

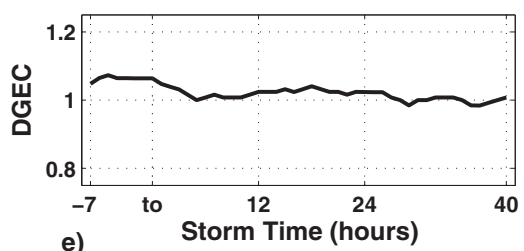

e)

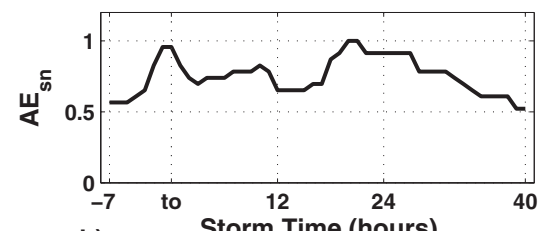

h)
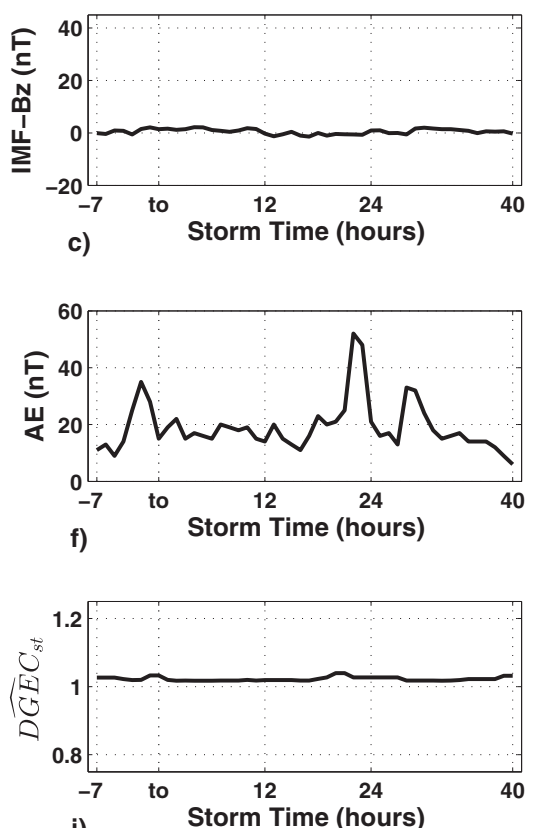

i)

Fig. 6. Example of non-storm period (a) IMF-B, (b) dB/dt, (c) IMF-Bz, (d) GEC, (e) DGEC, (f) AE, (g) $A E_{m e d}$, (h) $A E_{s n}$, (i) $\widehat{D G E} C_{s t}$.

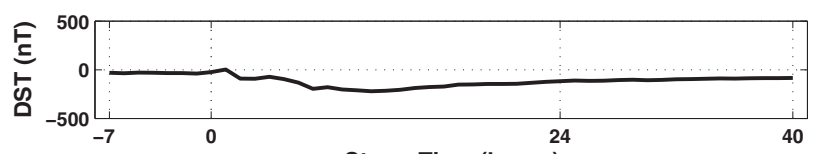

a) Storm Time (hours)

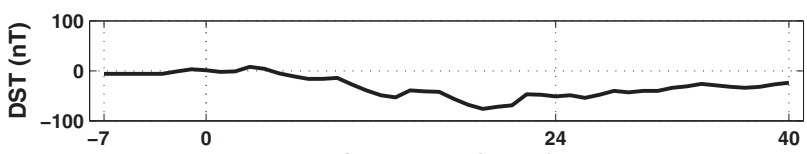

c) Storm Time (hours)

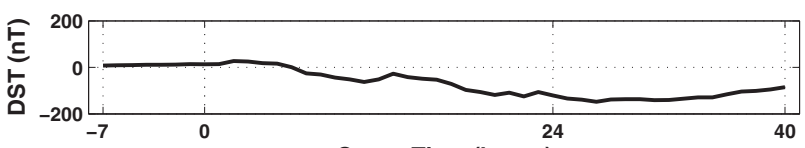

e) Storm Time (hours)
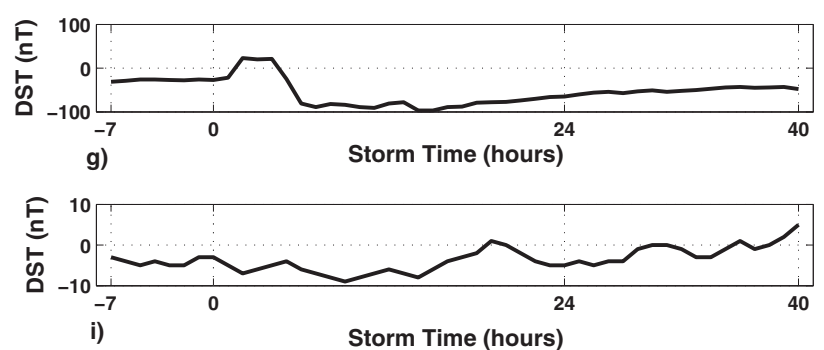
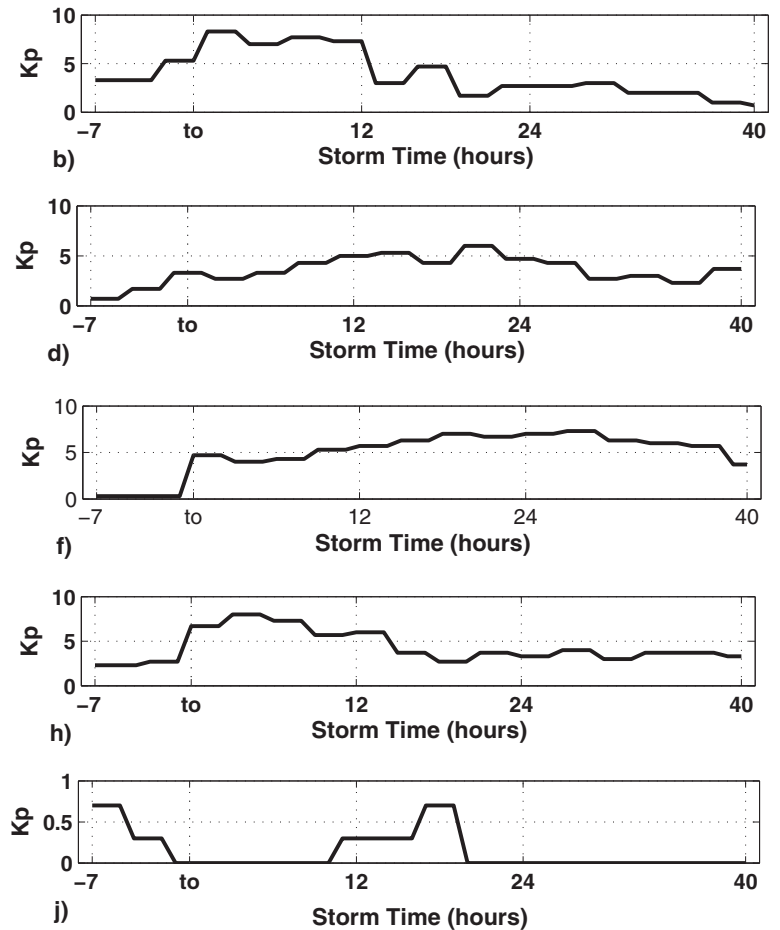

Fig. 7. For Storm 1 (a) Dst, (b) Kp, for Storm2 (c) Dst, (d) Kp, for Storm 3 (e) Dst, (f) Kp, for Storm 4 (g) Dst, (h) Kp, for the example of non-storm period (i) Dst, (j) Kp. 


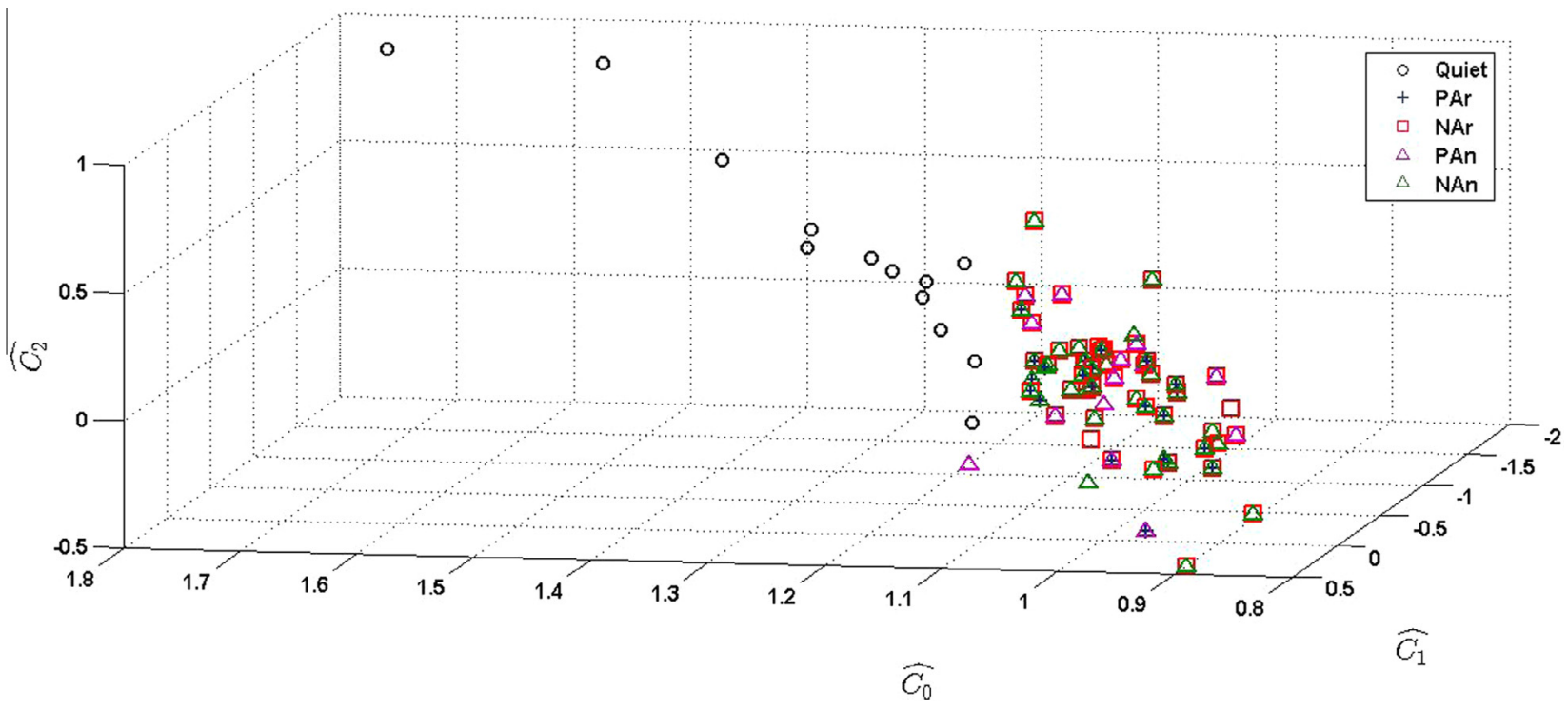

Fig. 8. Estimated model coefficients of 13 chosen non-storm periods $(\bigcirc)$ and $\operatorname{PAr}(+), \mathrm{NAr}(\square), \operatorname{PAn}(\diamond)$, and NAn $(\Delta)$ type AE storms between 1999 and 2013.
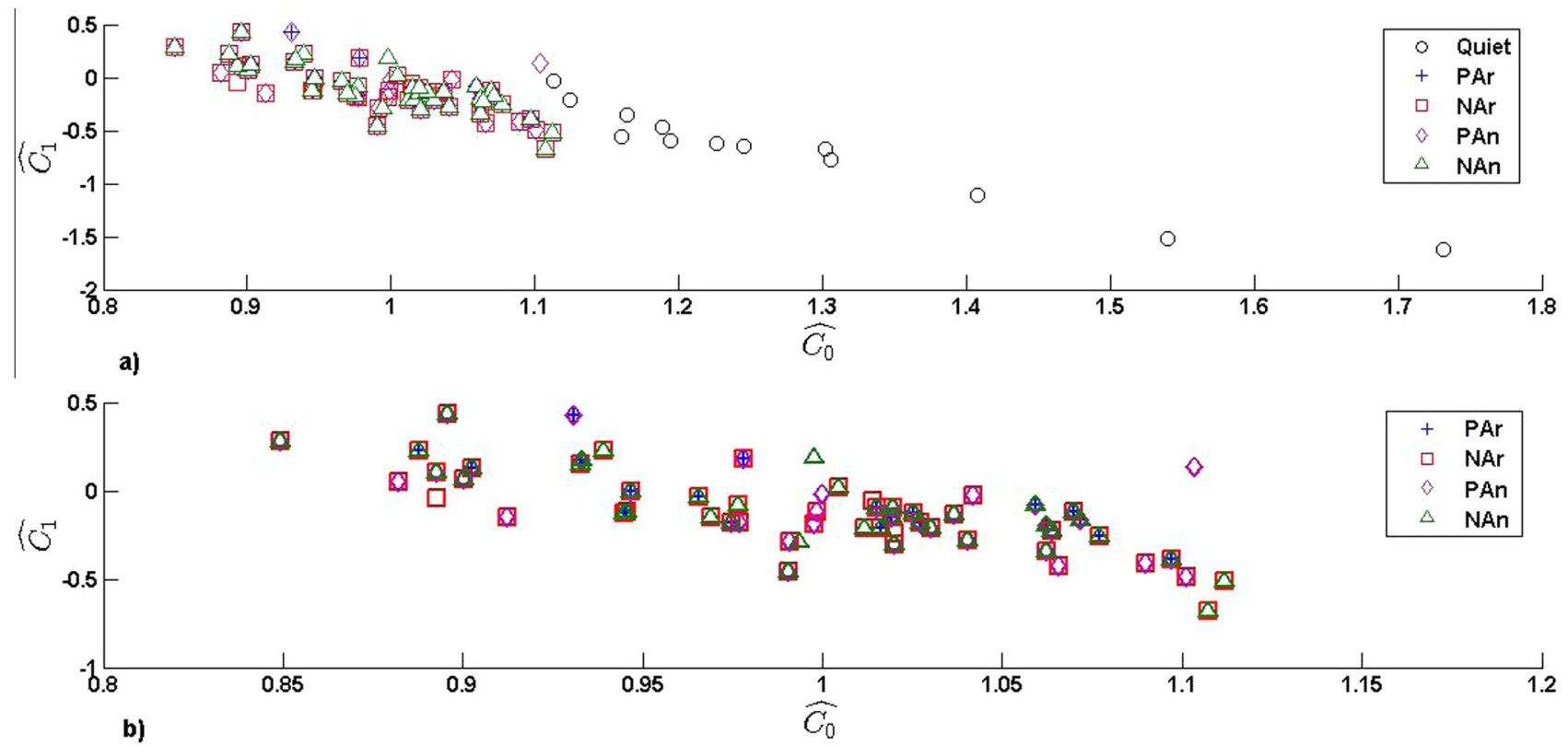

Fig. 9. (a) $\hat{C}_{0}$ and $\hat{C}_{1}$ values for 13 chosen non-storm periods $(\bigcirc)$ and $\operatorname{PAr}(+), \operatorname{NAr}(\square), \operatorname{PAn}(\diamond)$, and NAn $(\Delta)$ type AE storms between 1999 and 2013 , (b) $\hat{C}_{0}$ and $\hat{C}_{1}$ values for PAr $(+), \operatorname{NAr}(\square)$, PAn $(\diamond)$, and NAn $(\Delta)$ type AE storms between 1999 and 2013.

When the estimated coefficients are examined for the storms in Tables 1 and 3 and Figs. 2-5, it can be observed that the dominant coefficient is $\hat{C}_{0}$. The coefficients $\hat{C}_{1}$ and $\hat{C}_{2}$ are in the same order and they are one order of magnitude less compared to $\hat{C}_{0}$. The model error in Table 3 indicates that the proposed model in Section 3 is more appropriate in representation of positive and negative Arctic storms than Antarctic storms. The difference between model error and mean error indicates that when mean coefficients for storm times are used error increases and model is more consistent for negative storms. This may be due to the fact that $\mathrm{AE}$ is computed using the observatories close to the Arctic circle in the northern hemisphere (Kamide and Rostoker, 2004) while an asymmetric behavior of the Auroral Electrojet is observed in the Antarctic region (Weygand et al., 2014) .

The index values for the example non-storm period are provided in Fig. 6. During the example quiet period, $\mathrm{Kp}$ stays below 1 i.u. and Dst index is between -10 and $10 \mathrm{nT}$ as provided in Fig. 7.

The estimated coefficients of all PAr, NAr, PAn, and NAn storms between 1999 and 2013 which are determined 
to be an AE storm are provided in Fig. 8 along with the coefficients of 13 selected quiet periods for comparison. In Fig. 9, a close up to $\hat{C}_{0}$ and $\hat{C}_{1}$ are provided. In Fig. 9a, both storm and non-storm coefficient estimates and in Fig. 9b, only storm coefficient estimates are provided for better viewing.

It can be observed from Figs. 8 and 9 that although the coefficients of storm periods and non-storm periods vary, the most dominant coefficient is $\hat{C}_{0} \hat{C}_{0}$ indicates the level or nugget value of the model and shows the linear dependence of DGEC on the proxy AE. index $\hat{C}_{1}$ indicates the linear variability with respect to $\mathrm{AE}$ and quadratic dependence on proxy $\mathrm{AE}$ index can be observed by $\hat{C}_{2}$ Due to the fact that the polynomial model uses the normalized AE index, the intensity of the storm is not reflected to the proxy coefficients. The implemented storm conditions are highly successful in discriminating storm periods from non-storm times.

\section{Conclusions}

In this study, the variability of GEC is related to smoothed and normalized proxy AE index through a polynomial model. The coefficients of the polynomial are estimated in the least square sense for Positive Arctic, Negative Arctic, Positive Antarctic and Negative Antarctic storms that are grouped with respect to the Wp and $\mathrm{W}$-index. The storm/substorm onset times are determined with respect to the sudden increases in the magnitudes of IMF-B, $\mathrm{dB} / \mathrm{dt}$ and the negative inflection of IMF-Bz. $7 \mathrm{~h}$ sliding window median filter of AE provides a smoothed trend that indicates the increase in storm conditions. In order to separate the storms that affects AE, an extra condition is imposed by choosing the storms during which $A E_{\text {med }}$ becomes larger than $900 \mathrm{nT}$. The analysis is based on DGEC values computed from the GEC by taking the hourly ratio of 7 day median prior to the day of investigation. The smoothed AE is then normalized within the storm duration to computed proxy $A E_{s n}$ index. Proxy $A E_{s n}$ is then related to the unitless DGEC using the second order polynomial model. The model is applied to all AE storms that are included in the storm lists at IZMIRAN (2015) between 1999 and 2013 and 13 chosen non-storm periods. As indicated in the examples given in this study, the polynomial model is more successful in representing Arctic storms and the zeroth order polynomial coefficient that corresponds to the constant in the model is the most dominant contributor of the model.

\section{Acknowledgments}

The storm lists and GEC values are provided by http:// www.izmiran.ru/ionosphere/weather/storm/. AE, Dst and $\mathrm{Kp}$ indices are provided by Geomagnetism Data Service http://wdc.kugi.kyoto-u.ac.jp/wdc/. IMF-B and IMF-Bz are obtained from http://omniweb.gsfc.nasa.gov/form/ dx1.html. This study is supported by the joint grants from TUBITAK 112E568 and RFBR 13-02-91370-CT_a, and TUBITAK 114E092 and AS CR 14/001.

\section{References}

Afraimovich, E.L., Astafyeva, E.I., Oinats, A.V., Yasukevich, Y.V., Zhivetiev, I.V., 2008. Global electron content: a new conception to track solar activity. Ann. Geophys. 26 (2), 335-344.

Bowman, G.G., Mortimer, I.K., 2010. The delayed occurrence of equatorial ionospheric F2 layer post-sunset height decreases following auroral-zone substorm onsets. J. Atmos. Sol.-Terr. Phys. 72 (234-240), 2-3. http://dx.doi.org/10.1016/j.jastp.2009.11.016.

Buonsanto, M.J., 1999. Ionospheric storms-a review. Space Sci. Rev. 88 (563-601), 3-4.

Fuller-Rowell, T.J., Codrescu, M.V., Roble, R.G., Richmond, A.D., 1997. How does the thermosphere and ionosphere react to a geomagnetic storm? In: Tsurutani, B.T., Gonzalez, W.D., Kamide, Y., Arballo, J.K. (Eds.), Magnetic Storms. American Geophysical Union, Washington, D. C., pp. 203-225. http://dx.doi.org/10.1029/GM098p0203.

Davis, T.N., Sugiura, M., 1966. Auroral electrojet activity index AE and its universal time variations. J. Geophys. Res. 71, 785-801. http:// dx.doi.org/10.1029/JZ071i003p00785.

Deminova, G.F., Shashunkina, V.M., Goncharova, E.E., 1998. A global empirical model of effects of large-scale internal gravity waves in the night-time ionosphere. J. Atmos. Sol.-Terr. Phys. 60, 227-245. http:// dx.doi.org/10.1016/S1364-6826(97)00050-3.

Gulyaeva, T.L., Stanislawska, I., 2008. Derivation of a planetary ionospheric storm index. Ann. Geophys. 26 (9), 2645.

Gulyaeva, T.L., Stanislawska, I., 2010. Magnetosphere associated storms and autonomous storms in the ionosphere-plasmasphere environment. J. Atmos. Sol.-Terr. Phys. 72, 90-96.

Gulyaeva, T.L., Arikan, F., Hernandez-Pajares, M., Stanislawska, I., 2013. GIM-TEC adaptive ionospheric weather assessment and forecast system. J. Atmos. Sol. Terr. Phys. 102, 329-340.

Gulyaeva, T.L., Arikan, F., Stanislawska, I., 2014. Probability of occurrence of planetary ionosphere storms associated with the magnetosphere disturbance storm time events. Adv. Radio Sci. 12, 261-266. http://dx.doi.org/10.5194/ars-12-261-2014.

Gulyaeva, T.L., Veselovsky, I.S., 2012. Two-phase storm profile of global electron content in the ionosphere and plasmasphere of the Earth. J. Geophys. Res. 117, A09324. http://dx.doi.org/10.1029/ 2012JA018017.

Gulyaeva, T.L., F. Arikan, S.D. Yenen and O. Arikan, 1-3 May 2015 Statistical investigation of ionospheric storm and substorm events using GEC and AE-index. In: Proc. of 14th Ionospheric Effects Symposium, Alexandria, VA, USA.

Hajkowicz, L.A., 1998. Longitudinal (UT) effect in the onset of auroral disturbances as deduced from AE index. Ann. Geophys. 16, 15731579.

Hajkowicz, L.A., 1999. Monitoring ionospheric response to auroral electrojet activity from sub-auroral to equatorial latitudes in the east Asian-Australian longitudinal sector over a solar cycle (1978-1986). J. Atmos. Sol.-Terr. Phys. 61, 857-866. http://dx.doi.org/10.1016/S13646826(99)00064-6.

Kamide, Y., Rostoker, G., 2004. What is the physical meaning of the AE index? Eos Trans. AGU 85 (19), 188-192. http://dx.doi.org/10.1029/ 2004EO190010.

Liu, L., Wan, W., Chen, Y., Le, H., 2011. Solar activity effects of the ionosphere: a brief review. Chin. Sci. Bull. 56 (12), 1202-1211.

IZMIRAN, 2015. <http://www.izmiran.ru/ionosphere/weather/storm/>.

Malik, R., Sarkar, S., Mukherjee, S., Gwal, A.K., 2010. Study of ionospheric variability during geomagnetic storms. J. Indian Geophys. Union 14 (1), 47-56.

Prölss, G.W., 1993. Common origin of positive ionospheric storms at middle latitudes and the geomagnetic activity effect at low latitudes. J. Geophys. Res.: Space Phys. 98 (A4), 5981-5991. 
Saba, M., Fares, M., Gonzalez, W.D., Clúa de Gonzalez, A.L., 1997. Relationships between the AE, Ap and Dst indices near solar minimum (1974) and at solar maximum (1979). Ann. Geophys. 15 (10), 1265-1270.

Schrijver, C.J., Kauristie, K., Aylward, A.D., Denardini, C.M., Gibson, S.E., Glover, A., Gopalswamy, N., Grande, M., Hapgood, M., Heynderickx, D., Jakowski, J., Kalegaev, V.V., Lapenta, G., Linker, J.A., Liu, S., Mandrini, C.H., Mann, I.R., Nagatsuma, T., Nandi, D., Obara, T., O’Brien, T.P., Onsager, T., Opgenoorth, H.J., Terkildsen, M., Valladares, C.E., Vilmer, N., 2015. Understanding space weather to shield society: a global road map for 2015-2025 commissioned by COSPAR and ILWS. Adv. Space Res. 55 (12), 2745-2807.
Tsagouri, I., Belehaki, A., 2008. An upgrade of solar-wind-driven empirical model for the middle latitude ionospheric storm-time response. J. Atmos. Sol. Terr. Phys. 70, 2061-2076.

Weygand, J.M., Zesta, E., Troshichev, O., 2014. Auroral electrojet indices in the Northern and Southern Hemispheres: a statistical comparison. J. Geophys. Res. Space Phys. 119, 4819-4840. http://dx.doi.org/10.1002/ 2013JA019377.

Zhao, B., Wan, W., Liu, L., Mao, T., 2007. Morphology in the total electron content under geomagnetic disturbed conditions: results from global ionosphere maps. Ann. Geophys. 25, 1555-1568. 